\title{
Gesuch um Überlassung \\ Pirogoff'scher oder Chopart'scher Stümpfe, geheilter Frakturen und ankylotischer Gelenke.
}

\author{
Eine Bitte an die Herren Fachgenossen \\ von \\ Dr. B. Solger, \\ ao. Prof. der Anatomie in Greifswald.
}

Mit 1 Figur im Text.

Die bisher vorliegenden Untersuchungen von Stümpfen, welche durch die Ausfuhrung der Pirogoff'schen Operation oder ihrer Varianten sich ergeben hatten, wurden, so viel ich bisher ermitteln konnte, von Praktikern ausgefülitt und zwar in erster Linie von dem Gesichtspunkt aus, den Zeitpunkt und die Modalitäten der Vereinigung der beiden sich berührenden Sägeflächen (der Tibia und des Calcaneus) festzustellen. Dem Chirurgen kommt es ja natïrlich vor Allem darauf an, einen zum Gehen und Stehen brauchbaren Stumpf zu erzielen.

Nun wird aber in Folge dieses operativen Eingriffes der zurickbleibende Theil des Caleaneus um eine horizontale Achse nach aufwärts gedreht und dadurch derart verlagert, dass seine statische Beanspruchung nothwendig eine andere werden muss, als bei dem intakten und in normaler Lage verharrenden Fersenbein. Dasselbe gilt für gewisse Partien der Tibia, nämlich für diejenige Ecke, welche nach vollzogener Verwachsung der Sägeflächen ohne direkte knöcherne Unterlage bleibt (in der heigegebenen Figur bei $v$ ). Es fragt sich nun: Wie reagiren die genannten Knochentheile anf eine solche Veränderung ihrer Beanspruchung?

Dass eine auf eine größere Reihe von Objekten ausgedehnte Untersuchung Ergebnisse zu liefern rerspricht, welche für die Entwickelungsmechanik nicht ohne Bedeutung sein werden, dürfte schon aus der hier folgenden Skizze eines solchen Falles, der mir 
ans dem Leichenmaterial des hiesigen auatomischen Instituts von Herrn Geheimrath Professor Dr. Somser guitigst zur Verfügung gestellt wurde, ersichtlich sein. Hier iiberlebte das Individuum, dessen untere Extremititen, wie es scheint ich konnte nur die rechte untersuchen), beide den gleichen operativen Eingriff erlitten hatten, nach der mir zu Theil gewordenen Information noch um volle 11 Jahre die Operation, und doch macht es, wenn wir von der den hinteren Winkel zwischen ehemaliger Corticalis der Tibia

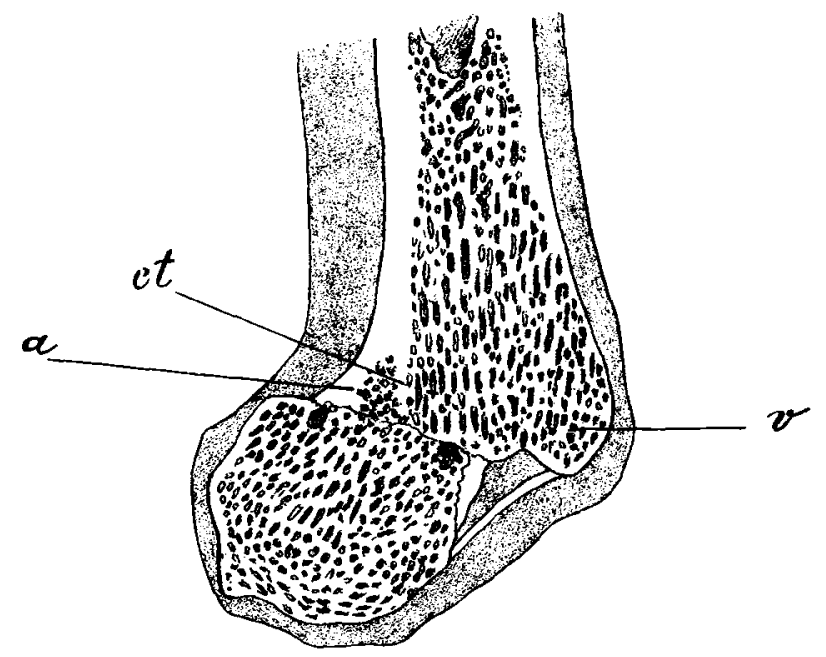

ia $t$ und Calcaneus ausfullenden Knochenmasse $(a)$ absehen, ganz den Eindruck, als seien die frisch abgesägten Knochenendeu soeben mit einander verlöthet.

Ein zweiter Fall dieser Art, der mir vou Herru Kollegen NaUwerck Königsberg i. Pr. in zurorkommendster Weise zur wissensehaftlichen Verwerthung ïbersandt wurde, zeigt ein ähnliclies konservatives Verhalten der Knochenbälkchen zu beiden Sieiten der Verwachsungsflaiche. Er stammt aus der Praxis des Herm Geheimrath Dr. Herscunin (Rauden, der bei einem trbeiter, der eine \%erschmetterung des eineu Fußes erlitten hatte, zur Vornahme der PIRogoff'schen Operation schreiten musste. Der stumpf funktionirte, wie mir gütigst mitgetheilt wurde, vortrefflich, bis etwa $\bar{i}$ Jahre nach der Operation dem Leben des betreffenden Individuum dureh einen Unfall ein jähes Ende bereitet wurde. Auch hier hat sich die vordere, den Calcaneus etwas überragende Ecke der Tibia wie 
in der Figur bei $v$ ) mit den charakteristischen langgestreckten Spongiosamaschen in ihrer ursprünglichen Ausdehnung erhalten, die Ausftullung des hintern Winkels zwischen Tibia und Calcaneus, die anch ADLOFF (1868) abbildet, ist gleichfalls nachweisbar, wenn sie auch weniger voluminös erscheint, als dort.

Bei der makroskopischen Untersuchung des Objektes darf man jedoch nicht stehen bleiben: sie muss vielmehr durch das Mikroskop kontrollirt und ergänzt werden. Richtung und Anordnung der Knochenhöhlen und Fibrillen, Verhalten der sog. Kittlinien (v. Enver), Vorkommen Howship'scher, nicht ausgefüllter Lakunen, alle diese Momente müssen bericksichtigt werden, will man anders darauf rechnen, einen Einblick in die Causalität des Knochenaufbaues zu erhalten.

Ich erlaube mir nun die höfliche Bitte an die Herren Fachgenossen zu richten, der von mir begonnenen Untersuchung, die ubrigens an früher veröffentlichte Arbeiten (1892-1894) eng sich anschließt, gutigst gedenken zu wollen, falls ihnen derartiges Material zugehen sollte. Auch für die Überweisung CHopar'T'scher Sttimpfe, geheilter Frakturen und ankylotischer Gelenke ') wäre ich sehr dankbar, wie ich mich schon jetzt den Herren, die so freundlich waren, mich mit Material zu unterstiitzen, verpflichtet fuhle. An einem von Herrn Geheimrath Prof. Dr. STreda (Königgberg i./Pr.) mir gutigst ubermittelten CHOPART'schen Stumpf fand ich die bekannte, etwas excentrisch zwischen den drei Spongiosaztigen gelegene Lücke von normaler Größe, obwohl sie gerade senkrecht oberhalb der am meisten nach unten prominirenden Vorragung sich befand, mit der die untere Fläche des Calcaneus den Boden berührte. Auf das Verhalten dieser Lücke wird bei Untersuchnng ähnlicher Fälle in Zukunft wohl zu achten sein.

Greifswald (Gutzkowerstr. 31), im Januar 1895.

1) Herrn Prof. v. Tönök (Budapest) statte ich einstweilen an dieser Stelle für die gütige Übersendung eines ankylotischen Kniegelenks, welches anch die von Köster zuerst signalisirten Veründerungen der Diaphyse des Femur und der Tibia in schönster Ausbildung zeigt, meinen verbindlichsten Dank ab. 